\section{Compliance with ethical standards}

Conflict of interest A.S. is an Innovator of MII Ret Cam. None of the other authors have the conflict of interest with this submission

\section{References}

1. Chan CK, Tarasewicz DG, Lin SG. Relation of pre-LASIK and post-LASIK retinal lesions and retinal examination for LASIK eyes. Br J Ophthalmol. 2005;89:299-301. 2
2. Roger Collier. Educating patients with pictures. CMAJ. 2011;183:e1094.

3. Katz MG, Kripalani S, Weiss BD. Use of pictorial aids in medication instructions: a review of the literature. Am J Health Syst Pharm. 2006;63:2391-7.

4. Chan HK, Hassali MA, Lim CJ, Saleem F, Tan WL. Using pictograms to assist caregivers in liquid medication administration: a systematic review. J Clin Pharm Ther. 2015;40:266-72.

5. Paasche-Orlow MK, Schillinger D, Greene SM, Wagner EH. Health care systems can begin to address the challenge of limited literacy. J Gen Intern Med. 2006;21:884-7.

\title{
The effect of statin exposure on choroidal neovascularization in nonexudative age-related macular degeneration patients
}

\author{
Nitya Rajeshuni ${ }^{1}$ - Cassie A. Ludwig ${ }^{2}$ - Darius M. Moshfeghi $\mathbb{1}^{2}$ \\ Received: 8 June 2018 / Revised: 30 June 2018 / Accepted: 13 July 2018 / Published online: 17 August 2018 \\ (c) The Royal College of Ophthalmologists 2018
}

Age-related macular degeneration (AMD) is the leading cause of blindness above age 65 in industrialized countries [1]. While early-stage (nonexudative) AMD is characterized by drusenoid deposits that typically do not affect vision, late-stage AMD consists of geographic atrophy (GA) or choroidal neovascularization (CNV, also known as exudative AMD) which can cause significant vision loss.

While antioxidant AREDS vitamins are currently most commonly prescribed for nonexudative AMD, no standard treatment has been established [2]. However, AMD shares several risk factors with atherosclerosis and may have similar pathophysiology [1]. Therefore, statins ( $\beta$-hydroxy $\beta$-methylglutaryl-CoA [HMG-CoA] reductase inhibitors) have been hypothesized as a potential treatment. Research thus far on this topic has been contradictory. $\mathrm{CNV}$ in particular is not well understood with fewer relevant trials and observational studies $[3,4]$. In a recent prospective cohort of 26 patients on high-dose atorvastatin $(80 \mathrm{mg}), 10$ showed

Darius M. Moshfeghi

dariusm@stanford.edu

Stanford University School of Medicine, Stanford, USA

2 Department of Ophthalmology, Byers Eye Institute, Stanford University School of Medicine, Stanford, USA drusen regression, while none progressed to $\mathrm{CNV}$ [4]. Large-scale retrospective studies are needed to investigate this further, a gap our study addresses.

Using the Stanford University Medical Center (SUMC) Clinical Data Warehouse, we performed a crosssectional study of patients with nonexudative AMD seen at SUMC since 2008. Subjects were identified using ICD9/ICD-10 codes 362.51/H35.31. The influence of statin exposure and covariates age, gender, race, and presence of comorbidities (ICD-9/ICD-10 codes for hypercholesterolemia, hypertension, cardiovascular disease, or cerebrovascular disease) on development of CNV (ICD-9/ ICD-10 362.52/H35.32) were examined using crude bivariate analyses (chi-squared) and multivariate logistic regression. Statistical assumptions were met. The protocol was approved by the Stanford University Institutional Review Board.

The study population included 3090 patients (Table 1). Approximately half $(49.7 \%)$ were on statins and $26.3 \%$ developed CNV. Those on statins tended to be older $(67.8 \%$ $\geq 80$ ), White (77.5\%), and have more comorbidities (84.4\%). A larger proportion of statin users developed CNV (29.3\%) compared to non-statin users (23.3\%). Multivariate logistic regression analysis adjusting for age, sex, race, and comorbidity status revealed statin users have increased odds of CNV (OR 1.27, CI 1.06-1.51) (Table 2). Subjects aged 
Table 1 Demographics of nonexudative age-related macular degeneration patients by statin exposure

\begin{tabular}{|c|c|c|c|c|c|}
\hline & Characteristic & $\begin{array}{l}\text { All patients } \\
(n=3090) \\
n(\%)\end{array}$ & $\begin{array}{l}\text { Statins } \\
(n=1535) \\
n(\%)\end{array}$ & $\begin{array}{l}\text { No statins } \\
(n=1555) \\
n(\%)\end{array}$ & $p$-value \\
\hline \multicolumn{6}{|c|}{ Age } \\
\hline & $<80$ & $1105(35.8)$ & $495(32.2)$ & $610(39.2)$ & $<0.0001$ \\
\hline & $\geq 80$ & $1985(64.2)$ & $1040(67.8)$ & $945(60.8)$ & \\
\hline \multicolumn{6}{|c|}{ Sex } \\
\hline & Female & $1905(61.7)$ & $840(54.7)$ & $1065(68.5)$ & $<0.0001$ \\
\hline & Male & $1185(38.3)$ & $695(45.3)$ & $490(31.5)$ & \\
\hline \multicolumn{6}{|c|}{ Race } \\
\hline & White & $2320(75.1)$ & $1190(77.5)$ & $1130(72.7)$ & 0.0018 \\
\hline & Non-White & $770(24.9)$ & $345(22.5)$ & $425(27.3)$ & \\
\hline \multicolumn{6}{|c|}{$\begin{array}{l}\text { Comorbid } \\
\text { conditions }\end{array}$} \\
\hline & None & $1035(33.5)$ & $240(15.6)$ & $795(51.1)$ & $<0.0001$ \\
\hline & Hypercholesterolemia & & & & \\
\hline & Hypertension & & & & \\
\hline & Cardiovascular disease & & & & \\
\hline & Cerebrovascular disease & $2055(66.5)$ & $1295(84.4)$ & $760(48.9)$ & \\
\hline \multicolumn{6}{|c|}{ Statin use } \\
\hline & No statins & $1555(50.3)$ & - & - & \\
\hline & Statins & $1535(49.7)$ & - & - & \\
\hline \multicolumn{6}{|c|}{$\mathrm{CNV}$} \\
\hline & No CNV & $2278(73.7)$ & $1085(70.7)$ & $1193(76.7)$ & 0.0001 \\
\hline & $\mathrm{CNV}$ & $812(26.3)$ & 450(29.3) & 362(23.3) & \\
\hline
\end{tabular}

$C N V$ choroidal neovascularization

Table 2 Characteristics associated with choroidal neovascularization in nonexudative age-related macular degeneration patients

\begin{tabular}{|c|c|c|c|c|c|}
\hline & \multirow[t]{2}{*}{ Characteristic } & \multicolumn{2}{|l|}{ Unadjusted } & \multicolumn{2}{|l|}{ Adjusted } \\
\hline & & Odds ratio & $95 \% \mathrm{CI}$ & Odds ratio & $95 \% \mathrm{CI}$ \\
\hline \multicolumn{6}{|c|}{ Age } \\
\hline & $<80$ & 1.00 [Reference] & & 1.00 [Reference] & \\
\hline & $\geq 80$ & 2.97 & 2.45 to 3.61 & 2.82 & 2.32 to 3.44 \\
\hline \multicolumn{6}{|l|}{ Sex } \\
\hline & Female & 1.00 [Reference] & & 1.00 [Reference] & \\
\hline & Male & 0.87 & 0.74 to 1.03 & 0.85 & 0.71 to 1.01 \\
\hline \multicolumn{6}{|c|}{ Race } \\
\hline & White & 1.00 [Reference] & & 1.00 [Reference] & \\
\hline & Non-White & 0.47 & 0.38 to 0.58 & 0.50 & 0.40 to 0.61 \\
\hline \multicolumn{6}{|c|}{ Statin use } \\
\hline & No statins & 1.00 [Reference] & & 1.00 [Reference] & \\
\hline & Statins & 1.37 & 1.16 to 1.61 & 1.27 & 1.06 to 1.51 \\
\hline \multicolumn{6}{|c|}{$\begin{array}{l}\text { Comorbid } \\
\text { conditions }\end{array}$} \\
\hline & None & 1.00 [Reference] & & 1.00 [Reference] & \\
\hline & Hypercholesterolemia & & & & \\
\hline & Hypertension & & & & \\
\hline & Cardiovascular disease & & & & \\
\hline & Cerebrovascular disease & 1.38 & 1.16 to 1.65 & 1.02 & 0.84 to 1.25 \\
\hline
\end{tabular}

$\geq 80$ (OR 2.82, CI 2.32-3.44) and White (Reference NonWhite: OR 0.50 , CI $0.40-0.61$ ) were also more likely to develop CNV after controlling for covariates. Interestingly, comorbidity effects disappeared after multivariate adjustment (OR 1.02, CI 0.84-1.25).

This cross-sectional study adds to the growing literature around the therapeutic potential of statins in preventing AMD progression. Advanced AMD prevalence estimates for GA vs. CNV range from $1: 1$ to $2: 1$; however, GA currently has no treatment [5]. As suggested by
Miller et al. statins may allow for drusen regression potentially circumventing GA [4]. Therefore, if statins are associated with CNV as indicated in our study, this is a small exchange given vision can be well preserved in these patients with existing therapies like anti-VEGF (vascular endothelial growth factor) [1]. Our study is a preliminary exploration of statin effect on CNV. The observed association is likely complicated by treatment and risk factors unavailable in our database and could be subject to residual confounding. Large cohort studies and 
randomized controlled trials incorporating risk and treatment factors (dose, class, course length, hydrophilicity) are necessary [4]. In conclusion, given the global disease burden and grave implications of advanced AMD, novel treatment with statins deserves further study and consideration.

Funding This work was supported by a Medical Scholars Grant, a medical student research grant awarded from the School of Medicine at Stanford University.

\section{Compliance with ethical standards}

Conflict of interest The authors declare that they have no conflict of interest.

\section{References}

1. Gehlbach P, Li T, Hatef E. Statins for age-related macular degeneration. Cochrane Database Syst Rev. 2015;2:CD006927.
2. Age-Related Eye Disease Study Research Group A-REDSR. A randomized, placebo-controlled, clinical trial of high-dose supplementation with vitamins $\mathrm{C}$ and $\mathrm{E}$, beta carotene, and zinc for agerelated macular degeneration and vision loss: AREDS report no. 8. Arch Ophthalmol. 2001;119:1417-36.

3. Maguire MG, Ying G, McCannel CA, Liu C, Dai Y, Complications of Age-Related Macular Degeneration Prevention Trial (CAPT) Research Group. Statin use and the incidence of advanced agerelated macular degeneration in the complications of age-related macular degeneration prevention trial. Ophthalmology. 2009;116:2381-5.

4. Vavvas DG, Daniels AB, Kapsala ZG, Goldfarb JW, Ganotakis E, Loewenstein JI, et al. Regression of some high-risk features of agerelated macular degeneration (AMD) in patients receiving intensive statin treatment. EBioMedicine. 2016;5:198-203.

5. Wenick AS, Bressler NM, Bressler SB. Age-related macular degeneration: non-neovascular early AMD, intermediate AMD, and geographic atrophy. In: Schachat AP, Wilkinson CP, Hinton DR, Sadda SR, Wiedemann P, editors. Ryan's retina. 6th ed. Philadelphia, PA: Elsevier, 2018. Chapter 68.

\title{
Van gogh and the obsession of yellow: style or side effect
}

\author{
Doğaç Demir ${ }^{1}$ · Şefik Görkey²
}

Received: 14 January 2018 / Revised: 19 July 2018 / Accepted: 7 August 2018 / Published online: 7 September 2018

(c) The Royal College of Ophthalmologists 2018

Vincent Van Gogh is well known for his yellow addiction, which might be related to a health condition [1]. There are several theories about his possible diseases, including epilepsy, Meniere's disease, and acute intermittent porphyria [2-6].

This yellow obsession makes professionals wonder: were those only reflection of his mind or how he saw the world?

There are different theories around this however, this hypothesis will focus on one theory: Xanthopsia. Xanthopsia is a rare condition that causes yellow vision which can also occur due to medications. Digitalis rarely causes

Doğaç Demir

dogacdemir@gmail.com

Marmara University, School of Medicine, İstanbul, Turkey

2 Medical History and Ethics Department, Marmara University, School of Medicine, İstanbul, Turkey yellow vision following bilirubin deposition in the eye which possibly explains his yellow addiction according to some specialists [7-9]. It is well known that he was treated by the famous physician Paul Gachet during the 19th century (Fig. 1). During that time foxglove plant, which is the main ingredient of digitalis, was used for the treatment of epilepsy and mania [2, 10-13].

Although, we don't have the medical recordings of him, it is possible that Gachet used digoxin on him considering Gogh painted him several times with foxglove plants $[2,14,15]$.

Moreover, the yellow color dominates his paintings he painted during his hospital stay.

Although there are several reasons to consider this yellow love is not natural, the opposite seems more reliable because of several reasons.

First, his treatment under Gachet lasted only 2 months. Studies suggest 2 months are not enough for the development of xanthopsia [16]. 